\title{
Modernização da gestão pública no Chile: progressos e desafios
}

\section{Claudio Orrego Larrain}

\section{Introdução}

Este documento apresenta uma breve descrição da maneira pela qual o Chile abordou a modernização da gestão pública, os principais progressos na matéria durante os últimos anos e uma resenha das tendências mundiais em cada uma das dimensões aqui consideradas.

Em primeiro lugar, desceve-se o problema, identificando-se o modelo histórico de gestão pública de nosso país e as principais rupturas que o Estado chileno enfrenta.

Logo após, as dimensões da modernização da gestão pública são sistematizadas como forma de simplificar a visualização do problema e, ao se considerar as relações metodológicas e sinergias entre áreas, mostra-se como essas dimensões se desagregaram em relação a certas linhas de ação.

Por último, apresenta-se um breve resumo dos progressos havidos nos últimos anos bem como os fatores críticos do sucesso, os focos institucionais de poder, resistência à mudança, as iniciativas modernizadoras e, finalmente, as fontes internacionais de apoio econômico e político.

\section{Modelo histórico de gestão pública no Chile}

\subsection{Variáveis criadoras de um contexto cultural}

A maneira de fazer as coisas no Estado chileno foi condicionada por vários fatores:

Traduzido por René Loncan 
a) $\mathrm{O}$ direito administrativo e a supervigilância que dele faz objeto a Controladoria Geral da Republica: o direito administrativo é um ramo do direito que argumenta ser a validade legal e a legitimidade das ações no setor público basicamente uma função do grau de adesão das mesmas aos procedimentos estabelecidos para sua realização. Realmente, toda ação realizada por um funcionário público competente, no âmbito de suas funções, se transforma num ato administrativo válido e legítimo, mais por sua mera sujeição à lei, regulamento ou à instrução do que pelos seus resultados e sua coerência com os objetivos propostos.

Estes princípios, firmemente aplicados pela Controladoria chilena, fizeram com que a cultura da administração pública se caracterizasse por um cumprimento formal, mas, efetivo, da lei (o que não é pouco, se considerarmos os baixos índices de corrupção do Chile no contexto internacional e latino-americano). ${ }^{1}$ Contudo, o conceito de uma gestão bem sucedida não se conseguia estender até o conceito de resultados devidamente planejados e avaliados, limitando-se a uma gestão centrada meramente em procedimentos formais. Um efeito do que precede é a consolidação de uma cultura burocrática avessa ao risco e contrária à inovação, uma vez que qualquer desvio de um procedimento preestabelecido, para além dos benefícios que possa trazer em seu bojo, está exposto à punição, como se fosse o mais grave atentado contra o Estado de Direito.

b) A relativa inamovibilidade dos funcionários públicos: este fato, além de seus propósitos fracassados em garantir um aparato público meritocrático ou apolítico, conseguiu, ao invés disso, consagrar a máxima difundida entre os funcionários públicos chilenos: "quem nada faz nada teme". Realmente, por ser extremamente difícil despedir funcionários, por não haver sistemas eficazes de mensuração do desempenho e por ser a antigüidade o único fator relevante para promoção nas carreiras da função pública, fortalecem-se os incentivos para nada fazer. Por que arriscar uma carreira, que nunca será truncada por um desempenho medíocre, em troca de uma atitude empreendedora e inovadora, para melhorar um serviço no qual, diante da menor falta administrativa, ainda que involuntária, pode-se tudo perder? Neste esquema, o controle da gestão e a avaliação do desempenho são definitivamente cruciais, mas objeto de muita resistência.

c) A desigualdade de rendas entre o setor público e o privado, especialmente no nível de profissionais qualificados, do alto escalão ou gestores. Um aspecto tradicional que tem tido importantes efeitos sobre a qualidade da gestão pública chilena é o de que, desde os primórdios do Estado chileno, a função pública foi apanágio das famílias mais tradicionais e abastadas do país. Isso trouxe consigo a visão de que a função púbica devia desenvolver-se antes de mais nada como uma função 
desinteressada de serviço ao país. Essa concepção, juntamente com a má avaliação da gestão estatal, fez com que se considerasse que as rendas dos funcionários públicos de mais alto nível hierárquico não precisassem ser suficientemente altas para satisfazer as necessidades daqueles que ocupavam cargos públicos.

No entanto, com o passar do tempo e o desenvolvimento econômico do país, o abismo que separa as rendas dos altos profissionais e executivos públicos daquelas de seus homólogos do setor privado foi aumentado até níveis considerados perigosos para a idoneidade e a transparência do sistema de remuneração dos altos escalões da função pública chilena. Com efeito, diferenciais muito grandes em matéria de remunerações terminam inexoravelmente acarretando problemas em termos do recrutamento e/ou retenção de bons elementos, como também da transparência nas formas que são utilizadas para remunerar de maneira adequada os altos escalões.

d) A nomeação política para todos os cargos de direção do Estado: da mesma maneira, o grau de politização da administração pública contribuiu para gerar uma "cultura do rateio", ou seja, a nomeação para cargos-chave levando-se em conta a militância política como a principal (e por vezes a única) variável. Esse tipo de comportamento, em sua expressão máxima, não se limitou somente aos cargos de direção, mas também àqueles que ocupam as funções mais elementares nos organismos públicos. Nesse sentido, produziram-se importantes distorções na administração do aparato público. A primeira é que, como os mais altos dirigentes dos organismos públicos são da exclusiva confiança do presidente da República, nem sempre se estabelece uma relação de agente-principal entre esses e seus respectivos ministros ou subsecretários, tornando difícil ou impossível uma avaliação de seu desempenho. A segunda é a confusão entre os papéis de formulação de políticas e de execução das mesmas. Finalmente, e talvez o mais importante, é que, ao ser a qualidade da gestão pública o cerne ou a pedra angular sobre a qual repousa o sucesso do processo de modernização da gestão pública, o fato de não se contar com pessoas, nos mais altos cargos de direção, que tenham habilidades gerenciais mínimas, coloca um obstáculo difícil de superar pela via da lei ou da regulamentação central.

e) Centralismo administrativo e territorial: o Chile é talvez um dos herdeiros mais fiéis do centralismo castelhano do século XVI. Com efeito, do ponto de vista territorial, administrativo, político, econômico e até cultural, o Chile tem um centro desproporcional em relação a regiões e localidades menores. Além dos esforços realizados durante as últimas décadas, o certo é que ainda se olha com muita desconfiança a capacidade profissional e administrativa daqueles que vivem longe da capital (Santiago 
tem 5 dos 15 milhões de habitantes do país). No âmbito da administração

pública, isto se traduz no fato de que, ao já conhecido verticalismo (e até autoritarismo) administrativo que existe como principal estilo de gestão, há que acrescentar-se esta desconfiança do centro em relação à periferia, com a conseqüente perda de criatividade e de eficácia que uma maior descentralização traria consigo. Uma das razões principais para justificar esse estado de coisas, e que não é um dado menor, tendo em vista o recorde latino-americano neste campo, é que qualquer descentralização acelerada poderia colocar em jogo os equilíbrios fiscais do país, que tanto custaram a ser alcançados e preservados.

\subsection{A história recente e os fatores da mudança}

Uma das particularidades do processo de modernização do Estado no Chile é o fato de que este foi impulsionado, consecutivamente, por dois governos de natureza muito diversa: um militar de direita e um democrático de centro-esquerda. A primeira onda de reformas centrouse no âmbito econômico. Isso se traduziu num dos primeiros e mais radicais programas de ajuste estrutural, de estabilização de preços e de abertura para o comércio exterior. Isso, obviamente, afetou a gestão do Estado, porém, mais em termos da enorme redução da despesa, do investimento e das remunerações. Contudo, o funcionamento do Estado seguiu seu curso tradicional, tendo entretanto de resistir a um dos embates ideológicos antiestatal mais brutais deste século. Posteriormente, e sempre no âmbito econômico, aprovou-se um plano agressivo de privatizações de empresas de ativos estatais. Sob a premissa de que tudo o que o Estado faz, é mal feito, e de que tudo o que o setor privado faz, é bem feito, procedeu-se à venda dos ativos públicos, lamentavelmente sem o acordo e a transparência que decisões tão importantes mereciam. Finalmente, a última inovação pretendeu criar um mercado para os seguros privados de saúde, privatizar o sistema de seguridade social e gerar um subsídio à demanda por educação básica e média. Com essas políticas, buscava-se gerar concorrência para os prestadores públicos, ou simplesmente tirar do Estado certas funções que, tradicionalmente, lhe cabiam.

A profunda crise social, política e econômica, do início dos anos 70, e os excessos, que se cometeram com relação ao papel onipresente do Estado em toda a vida social, estiveram na base dessas políticas. Precisamente devido à gravidade das crises que foram enfrentadas bem como ao radicalismo de algumas das reformas, o processo de modernização do Estado no Chile ficou estigmatizado pela natureza autoritária do governo militar e pelo tema (quase religioso para alguns) das privatizações. Com 
efeito, desde então, o debate nacional sobre a modernização do Estado reduziu-se a uma polêmica medíocre sobre o tamanho do Estado chileno, deixando absolutamente de lado as perguntas complexas e concretas sobre como um Estado contemporâneo pode mudar sua cultura, melhorar a produtividade, aumentar sua coordenação interna e externa e assim melhor servir aos cidadãos.

Como se pode observar na Tabela 1, o papel do Estado como produtor sofreu mudanças drásticas, no início da década de 70 e depois da crise dos anos 80, o que se explica, principalmente, pelas orientações dos governos das respectivas épocas. O primeiro, de Salvador Allende, orientado para o estabelecimento de um Estado socialista, e o segundo, de Augusto Pinochet, voltado para uma maior participação do mercado.

Tabelas 1: Empresas controladas pelo Estado

\begin{tabular}{|c|c|c|c|c|}
\hline \multirow{2}{*}{ Empresas } & \multicolumn{4}{|c|}{ Número de empresas por ano } \\
\hline & 1970 & 1973 & 1983 & 1989 \\
\hline Empresas ligadas à CORFO² & 46 & 228 & 23 & 14 \\
\hline Bancos & - & 18 & 1 & - \\
\hline Instituições financeiras & 2 & 2 & 2 & 2 \\
\hline Empresas públicas & 20 & 22 & 21 & 17 \\
\hline Empresas objeto de intervenção & - & 325 & - & - \\
\hline TOTAL & 68 & 595 & 47 & 33 \\
\hline
\end{tabular}

O contexto colocado, juntamente com o que foi mencionado acima, produziu, no início dos anos 90, um ambiente em que o setor público era sinônimo de ineficiência e esbanjamento, no qual preconizava-se que o Estado deveria ser reduzido a sua expressão mais mínima.

Em termos de política econômica, os governos da concertação ${ }^{3}$ centro-esquerda impulsionaram a economia social de mercado, tendo por base o conceito de um Estado regulador dos mercados, que focaliza seus esforços em necessidades sociais, e propuseram, assim, a sua retirada do papel de produtor direto de bens e serviços, para centrar-se mais (tanto em termos financeiros quanto de recursos humanos) na atenção a problemas da cidadania em áreas de especial sensibilidade social e política, tais como saúde, educação e outros novos temas da agenda pública como a qualidade de vida, o ordenamento territorial, a descontaminação e outros. $\mathrm{O}$ que precede fica demonstrado na Tabela 2. 
Tabela 2: Despesa social e em

bens e serviços: 1980-1996

\begin{tabular}{|l|c|c|c|c|c|c|}
\hline \multirow{2}{*}{ Despesa } & \multicolumn{5}{|c|}{ Percentagem da despesa total } \\
\cline { 2 - 7 } Países & \multicolumn{3}{|c|}{ Bens e serviços } & \multicolumn{3}{c|}{ Despesa social* } \\
\cline { 2 - 7 } & 1980 & 1996 & Variação & 1980 & 1996 & Variação \\
\hline Argentina & 57,1 & 22,4 & $-34,7$ & 28,6 & 65,1 & 36,5 \\
Bolívia & & 35,8 & - & & 40,8 & - \\
Brasil & 20,0 & 13,3 & $-6,7$ & 40,0 & 40,5 & 0,5 \\
Chile & 41,2 & 28,8 & $-12,4$ & 59,1 & 66,7 & 7,6 \\
Colômbia & 36,2 & & - & 44,3 & & - \\
\hline Costa Rica & 52,4 & 47,1 & $-5,3$ & 62,6 & 59,7 & $-2,9$ \\
Equador & 28,3 & 46,9 & 18,6 & 43,9 & & - \\
El Salvador & 49,7 & 50,8 & 1,1 & 34,2 & 36,6 & 2,4 \\
Guatemala & 49,7 & 51,8 & 2,1 & 31,6 & 39,3 & 7,7 \\
México & 31,8 & 26,1 & $-5,7$ & 44,3 & 50,2 & 5,9 \\
\hline Nicarágua & 60,0 & 30,0 & $-30,0$ & 33,5 & 46,8 & 13,3 \\
Paraguai & 60,9 & & - & 35,7 & & - \\
Peru & 44,7 & 37,5 & $-7,2$ & & \\
Uruguai & 47,6 & 29,4 & $-18,2$ & 62,3 & 76,1 & 13,8 \\
Venezuela & 50,2 & 20,0 & $-30,2$ & & & - \\
\hline
\end{tabular}

Fonte: Banco Mundial

* Inclui educação, saúde, seguridade social, bem-estar, habitação e lazer.

\subsection{A identificação da crise}

Considerando o precedente e o contexto político dos últimos 30 anos, é inegável que os consensos básicos sobre os quais o Estado chileno foi construído, durante este século, entraram em crise. Não se trata, como pretendem alguns discípulos da escola de Chicago, de que se esteja remoendo o que já se apregou por um longo espaço de tempo: que o Estado chileno não funciona bem, nem é capaz de fazê-lo. Muito pelo contrário, toda a evidência produzida por estudos sérios, como os da competitividade, do World Economic Forum, ou aqueles sobre corrupção, da Transparency International, expressam a boa situação relativa do Estado chileno. No entanto, estamos conscientes de que o Estado chileno atravessa hoje em dia uma crise que tem pelo menos quatro componentes, todos eles superáveis por meio de políticas adequadas e liderança política. Estes componentes são: 
1. A crise da missão e do papel: produzida fundamentalmente por uma lenta adequação do aparato estatal às mudanças do ambiente interno e externo verificadas nas últimas décadas. De modo especial, os limites entre o Estado, o setor privado e a sociedade civil começaram a tornar-se cada vez mais difusos e difíceis de diferenciar, o que, junto com um setor público lento em suas reações, gerou vazios funcionais que não foram preenchidos. Uma forma de superar as falsas dicotomias colocadas por um debate sobremodo carregado de conteúdo ideológico (mais Estado ou menos Estado) é chegar a um consenso, com visão de longo alcance, sobre quais são as funções que todos os chilenos concordam devam ser desempenhadas pelo aparato estatal (novas e tradicionais), bem como aquelas que não devam continuar a ser desempenhadas pelo mesmo, mas, sim pelo setor privado ou a sociedade civil.

2. A crise institucional: como conseqüência da crise anterior, necessita-se uma análise meticulosa a respeito da organização e das instituições que o Estado deve auto-proporcionar-se, para realizar, junto com o setor privado e a sociedade civil, sua missão. Novamente aqui a discussão não pode limitar-se ao tamanho do Estado. Trata-se de pensar nas novas funções, incluindo, por exemplo, o aumento das demandas dos cidadãos por maiores graus de participação democrática, e proceder-se à revisão da missão estratégica de cada instituição pública, adequando-a tal realidade. Isso, sem dúvida, significará a criação ou a adaptação de muitas repartições públicas, mas também significará a eliminação de outras tantas.

3. A crise da gestão: produto das características descritas na introdução deste artigo, a administração pública chilena deixou de estar sintonizada com as expectativas e demandas da cidadania. À sua pouca transparência habitual agora há que acrescentar-se casos incipientes de corrupção, de desatenção e pouca sensibilidade para com as demandas de usuários crescentemente exigentes (os pecados de ser monopólio), de excessiva tramitação burocrática para cidadãos e empresas cada vez mais competitivas no mundo, etc. A paciência da cidadania está acabando. É certo que não lhe interessa o debate sobre o Estado grande ou pequeno. No entanto, ela claramente toma partido quando se trata do Estado necessário e eficaz.

4. A crise da legitimidade: devido à crise antes descrita, e ao discurso anti-Estado dos últimos tempos, a cidadania foi abandonando sua adesão absoluta ao Estado. Segundo levantamentos realizados no Chile ${ }^{4}$ os cidadãos exigem cada vez mais do aparato público aquilo que o consumidor privado exige do mercado, ou seja, qualidade, competência profissional, tratamento digno e bom, boas informações, o direito de reclamar e de ser ouvido, etc. Não desejam mais ou menos Estado ou mais ou menos mercado. Desejam um Estado eficaz, que cumpra suas funções, e um mercado que produza bens e serviços a baixo preço e com boa qualidade. 


\section{Na direção de um novo modelo de gestão pública}

\subsection{Por que modernizar?}

Um dos fatores principais para explicar o processo de reforma que está ocorrendo é a liderança assumida na matéria pelo governo do presidente Frei. Rigorosamente falando, embora os cidadãos e o setor privado sejam cada dia mais críticos em relação à qualidade dos serviços do Estado, o certo é que essa temática ainda não se articulou como uma demanda cidadã ou corporativa dotada de poder. Em vista do que precede, pode-se argumentar que esse tenha sido um processo fortemente liderado pelo presidente da República, por dirigentes no nível intermediário, no Ministério da Fazenda e na Secretaria-Geral da Presidência, e por um grupo de gestores públicos altamente motivados e comprometidos com o tema.

As bases desse processo de modernização, para além das razões fiscais (que no caso do Chile são pouco convincentes, visto o superávit fiscal dos últimos anos), são de três tipos:

1. Éticas: além dos progressos econômicos realizados pelo Chile durante as duas últimas décadas, o certo é que para cada um chileno existem dois e meio chilenos que vivem em situação de pobreza ou de indigência. Nesse contexto, qualquer esbanjamento ou utilização ineficaz de recursos públicos constitui uma grave falta ética para com o País e, em especial, para com os mais pobres.

2. Políticas: a democracia se aprofunda à medida em que se reinventa a relação Estado-cidadão. Com efeito, saindo de uma relação paternalista e despótica, a nova gestão pública propõe um Estado voltado para os usuários e cidadãos, criando crescentes espaços para a participação, descentralizando o poder e a tomada de decisões, melhorando a qualidade da informação e a transparência das ações públicas, fazendo da satisfação do usuário um padrão de bom desempenho e tratando com dignidade os mais humildes, geralmente os que mais dependem do Estado. Da mesma forma, uma gestão pública moderna significa aumentar o acesso aos serviços públicos e conseqüentemente melhorar a igualdade de oportunidades.

3. Econômicas: a produtividade do setor público é um componente central da competitividade da economia como um todo. Para países pequenos como o Chile, que dependem de sua capacidade de concorrer num mundo cada vez mais globalizado e competitivo, qualquer aumento da competitividade tem impacto direto sobre sua capacidade de gerar riqueza e, conseqüentemente, desenvolvimento. 


\subsection{Obstáculos à modernização}

O processo de modernização da gestão pública, cuja gênese formal remonta à criação do Comitê Interministerial de Modernização da Gestão Pública, em 1994, teve de enfrentar múltiplos obstáculos. A respeito de alguns deles ainda subsiste a dúvida sobre quais poderão ser superados ou não. Os principais são os seguintes:

1) A ausência do sentido de urgência: esse é o obstáculo principal à modernização da gestão pública, ainda que por sua vez o mais contraditório. Em primeiro lugar, é óbvio que, se não há nenhum sentido de urgência para mudar algo tão lendário quanto a gestão pública, a reforma está condenada a ser política e tecnicamente inviável. No caso do Chile, esse foi, lamentavelmente, um fator que limitou a efetividade e a profundidade da mudança. Com efeito, o excelente desempenho fiscal do Chile durante os últimos dez anos (fator catalizador, por excelência, de processos de reforma da gestão pública), desempenha, no caso, um papel contrário. Há certo grau de consenso quanto a que o setor público gasta comparativamente pouco, e está bem organizado. Então, por que fazer mudanças? Nesse contexto, são outras políticas públicas as que monopolizam a atenção e a agenda pública (justiça, educação, infra-estrutura).

2) O poder dos sindicatos: tal como ocorre em muitos países, o último reduto do sindicalismo tradicional, organizado e poderoso, é o setor público. Mesmo sem serem muito poderosos no nível central, continuam exercendo grande capacidade de pressão no âmbito da educação e da saúde, que é exatamente onde as mudanças são mais necessárias.

3) Falta de clareza conceitual e política sobre o tema: uma das complexidades que teve o processo de modernização da gestão pública no Chile, é que a elite política (e inclusive a acadêmica) confunde sistematicamente a reforma do Estado (que inclui temas mais amplos, como a reforma política, econômica, social e administrativa) com a reforma específica da gestão. O problema desta confusão é que, com certa frequiência, esta última é avaliada em função de desafios ou de falhas da primeira. Da mesma forma, ao colocar todos os temas no mesmo cesto, termina-se politizando um conjunto de temas de gestão que, por sua natureza, deveriam ser de Estado. Finalmente, a elite política tende a menosprezar os benefícios políticos de curto prazo ligados a uma melhoria substancial da qualidade dos serviços públicos, sendo bastante avessa ao risco de reformas de gestão que podem ocasionar alguns custos trabalhistas.

4) Falta de um trabalho na área de comunicação: salvo raras exceções, os técnicos responsáveis por esse tipo de reforma consideram o tema da comunicação como algo secundário, mais próprio de políticos em campanha do que de funcionários públicos sérios. Pois bem, se isto é inexato ou incorreto de uma maneira geral, mais ainda no caso do Chile. 
Considerando-se o estigma da privatização que o período de governo dos

militares impôs ao termo modernização, o processo de modernização da gestão pública incentivado por governos democráticos devia ter feito um esforço sistemático e determinado desde o começo para esclarecer os verdadeiros fundamentos da reforma do Estado chileno e seu alcance real. Embora se tenha avançado muito nos últimos tempos, ter adotado desde o princípio ações de comunicação teria evitado suspeição ou resistências desnecessárias.

5) Fraca institucionalização do processo de reforma do Estado: apesar de o Comitê Interministerial de Modernização da Gestão Pública ter sido criado pelo presidente e estar composto pelos ministérios e organismos mais importantes do governo (Fazenda, Presidência, Interior, Trabalho, Economia, Secretaria-Geral da Presidência), o certo é que o mesmo não tem a base institucional que permita realizar de maneira ideal sua tarefa, pelo menos pelas seguintes razões: a) na prática, está longe do presidente; b) seu coordenador tem nível de chefe de divisão, não é um ministro; c) o fato de existirem muitos responsáveis termina significando nenhum; d) precariedade de meios, tanto financeiros e humanos quanto jurídicos.

\subsection{O novo modelo de gestão pública: linhas de ação}

O novo modelo de gestão pública que se concebeu para o Chile considera as dimensões mínimas de gestão para todos os tipos de organizações, incorporando as complexidades relacionadas aos organismos públicos e o mundo político. ${ }^{5}$ Neste sentido, as diretrizes da reforma e seus respectivos componentes são as que se enunciam abaixo:

- Sistema de gestão estratégica por resultados: sob esta linha de ação impulsionou-se um sistema de gestão para todo o governo, baseado no estabelecimento de instrumentos padronizados de planejamento anual e plurianual, abrangendo os alinhamentos político-estratégicos (presidente e Conselho de Gabinete), metas ministeriais (ministérios) e programas de melhoramento da gestão, com seus respectivos objetivos, metas de gestão e indicadores de resultado para todos os serviços públicos. Esses instrumentos são monitorados por uma equipe central, que presta contas duas vezes por ano e procede a uma avaliação seletiva de alguns casos. Os programas públicos são avaliados separadamente por meio de painéis realizados com peritos externos ao Estado e os seus resultados são divulgados publicamente, sendo enviados anualmente ao Congresso Nacional. O último elo deste sistema são as prestações de contas ao público de todos os resultados. A norma é que, junto com a prestação anual de contas que o presidente faz ao País, cada serviço público deve fornecer seu relatório 
integral de gestão; inclusive, recentemente, os relatórios de cada serviço devem estar à disposição do público em seu site na Web.

- Nova política de recursos humanos: em matéria de recursos humanos, que é uma das áreas mais deficitárias do plano de modernização, está-se incentivando quatro iniciativas de grande transcendência. A primeira delas é o estabelecimento de incentivos econômicos para os funcionários, traduzidos em aumentos anuais de remuneração. Estes incentivos são concedidos com base no desempenho individual, medido em função de sistemas de qualificação completamente reformados, e no desempenho coletivo, medido em função do grau de cumprimento dos programas de melhoria da gestão acima mencionados. O segundo componente foi o primeiro impulso com vistas a uma política descentralizada de treinamento, estabelecendo-se a obrigação de gastar $1 \%$ das remunerações, por serviço, em treinamento. O terceiro elemento está relacionado ao estabelecimento de incentivos à aposentadoria (aposentadorias voluntárias), a melhoria das condições de trabalho e a incorporação da necessidade de realização de concursos, como mecanismo privilegiado para preencher vagas em cargos médios ou altos na administração (isto está em processo de negociação). Finalmente, o presidente da República anunciou ao País a criação de um sistema de gerência pública. Este projeto, que busca a profissionalização da alta direção dos serviços do Estado, divide-se por sua vez em três partes: (1) uma concepção político-técnica de um sistema de recrutamento, remuneração e avaliação dos altos funcionários públicos com funções de direção, incluindo as correspondentes modificações legais; (2) uma experiência-piloto de treinamento e formação dos altos funcionários públicos, com funções de direção, no exercício de suas funções (mestrado em gestão pública para gestores executivos); (3) e, finalmente, um plano-piloto que integra a idéia de uma gestão orçamentária mais flexível com a obrigatoriedade de manter a contabilidade patrimonial e de melhorar os convênios de desempenho dos diversos serviços públicos. Nesse contexto, e como uma forma concreta de assegurar que aqueles que venham a dirigir os organismos públicos possam contar com as ferramentas necessárias para desincumbir-se das suas tarefas, da melhor maneira possível, estão sendo testados temas como prêmios à economia, a possibilidade de administrar ativos, estabelecer orçamentos multianuais e incorporar a contabilidade patrimonial.

- Qualidade dos serviços e participação dos cidadãos: paralelamente à aprovação de uma política governamental relativa ao assunto, e para além do muito que têm feito os responsáveis em seus próprios serviços, o governo está incentivando uma série de projetos transversais nesse domínio. Este fator é de grande importância no programa de modernização dos organismos do Estado, e não faz sentido se não se traduzir em melhorias concretas na qualidade de vida das pessoas. Nesse contexto, 
está-se incentivando a criação de protótipos de escritórios de informação

e de reclamações; a simplificação da tramitação burocrática; criação de cartilhas de direitos do cidadão para cada serviço; incentivos à inovação e ao melhoramento da qualidade (prêmios para as duas categorias); e, finalmente, a possibilidade de integrar a informação digitalizada numa janela única, ou então num terminal de acesso público.

- Transparência e probidade: junto com a modernização da legislação em matéria de probidade e com a aprovação da Convenção Interamericana contra a Corrupção, o governo e o Comitê se dedicam a três iniciativas de alto impacto: a primeira consiste na implementação plena do novo sistema de informações e de compras eletrônicas do Estado; a segunda consiste no estabelecimento de um defensor do cidadão que se preocupe com a proteção dos direitos dos cidadãos, diante dos atropelos originados de um exercício abusivo do poder; finalmente, a massificação da informação disponível por parte do Estado através da Internet.

- A nova institucionalidade: o domínio institucional é, juntamente com o dos recursos humanos, um dos dois terrenos em que menos fizemos progresso. No entanto, conseguiram-se avanços significativos em termos de desconcentração dos serviços públicos, da reformulação da institucionalidade reguladora do Estado e do redimensionamento dos ministérios que passaram a ter de desempenhar novas funções. Há que acrescentar-se a modernização institucional de várias organizações tradicionais do Estado, e um plano-piloto aprovado por lei, em virtude do qual se explorará um novo tipo de organização hospitalar, ao qual será concedido maior autonomia, capacidade de gestão e responsabilidade.

\subsection{Estratégia de implementação do plano de modernização}

A estratégia chilena de modernização da gestão pública se afastou da maioria dos processos de reforma do Estado, em dois importantes aspectos. Primeiro porque desde o início optou-se por um enfoque gradual da mudança, rompendo a tradição de reformas mais globais e rápidas. A principal razão para isso pode ser encontrada no fato de que, no caso do Chile, a reforma não foi motivada por sérias crises financeiras, como no caso dos exemplos mais conhecidos, entre eles a Nova Zelândia, a Inglaterra, o Uruguai, o Brasil, etc. ONo entanto, a estratégia de ir testando programas e políticas em planos-piloto, para logo avaliá-los, conceber novas políticas e daí implementá-los de maneira ampla, trouxe bons resultados.

O segundo terreno, em que há diferenciação com relação a outros processos de reforma do Estado, foi a subordinação dos temas de superestrutura e de institucionalidade àqueles mais próprios à reforma da gestão. A crença latina, de que é através de reformulações jurídicas 
e de superestrutura que se reforma a gestão, encontrou fortes detratores em várias experiências fracassadas (assim como na literatura). No caso do Chile, optou-se por privilegiar as reformas que potencializam a capacidade de gestão e os novos instrumentos de planejamento e de avaliação da gestão, que são precisamente os que, definitivamente, permitem que se mude as rotinas e a cultura das pessoas.

Outro fator crítico de sucesso na implementação do Plano Estratégico de Modernização da Gestão Pública foi a sua origem políticoinstitucional. Com efeito, tanto a criação do Comitê Interministerial de Modernização da Gestão Pública (grupo de alto nível político criado de forma $a d$ hoc para conceber e liderar um plano neste terreno), quanto o estabelecimento de uma aliança estratégica de trabalho entre as autoridades da Fazenda (em especial da Direção de Orçamento) e as autoridades do Ministério Secretaria-Geral da Presidência, foram fundamentais para a consecução dos objetivos colocados.

Da mesma forma, outro aspecto fundamental foi a criação de redes com atores relevantes das mais diversas disciplinas e áreas, que permitiram a geração de consensos, aproveitar as experiências bem sucedidas e aumentar os recursos humanos e financeiros envolvidos no processo. Aqui vale a pena mencionar as seguintes redes, que foram vitais para o processo:

— Executivos do serviço público: a criação do Comitê Interserviços de Modernização, composto pelos diretores e chefes dos 18 serviços públicos mais importantes do País, representou um apoio fundamental ao processo de modernização;

- O setor privado: a criação de um grupo de trabalho sobre a modernização da gestão pública, no contexto do Fórum de Desenvolvimento Produtivo (organismo tripartite composto de trabalhadores, empresários e representantes do Governo), onde se realizou um excelente trabalho de legitimação do setor público diante de importante segmento do setor produtivo;

- Universidades: também foi estabelecida uma mesa de trabalho com as diversas universidades vinculadas aos assuntos de gestão pública;

- Grupos informais de trabalho de alto impacto: um exemplo disto é o grupo que participou da viagem de estudos à Nova Zelândia, composto de políticos insignes, acadêmicos, membros de ONGs e executivos do setor público, que até hoje se reúnem para avaliar políticas relativas à modernização do Estado;

- Outras redes internas do setor público: a rede de formadores de recursos humanos do setor público; a rede de comunicadores, composta dos encarregados das comunicações dos diferentes ministérios e serviços públicos. 
Outro aspecto de grande importância na elaboração e na implementação das iniciativas de modernização foi a coordenação e a utilização de parte da capacidade instalada e de recursos humanos de outros ministérios e organismos públicos, o que permitiu executar-se projetos, contar com uma capacidade de gestão e obter resultados que dificilmente poderiam ser alcançados.

Finalmente, e o que é mais importante, há que mencionar-se a capacidade de comunicar o sentido e a visão da mudança, não apenas aos cidadãos e aos próprios funcionários públicos, mas também, de forma muito especial, aos dirigentes máximos e à classe política. Com relação a estes últimos, foi necessário vincular muitas das reformas que, por definição, são de longo prazo, a resultados e a demandas políticas de curto prazo. Em outras palavras, tentou-se demonstrar que, ter ou não ter um Estado de excelência em funcionamento, não é uma questão neutra com relação à capacidade de um governo ser bem avaliado por suas políticas ou por sua capacidade de reagir diante de problemas públicos.

No caso dos funcionários, uma forma de comunicar a visão e o porquê da mudançaocorreu mediante um forte investimento em instâncias de difusão de experiências nacionais e internacionais, e em programas de mudança cultural. Para o primeiro esforço, utilizou-se seminários, congressos e as versões anuais da Exposição Anual de Modernização e do Seminário Internacional sobre a Modernização do Estado. Para o segundo esforço, optou-se mais por recorrer a projetos de trabalho por serviço, nos quais o traço comum é a convicção de que, sem mudança das pessoas, não há reforma do Estado que perdure no tempo.

Sem prejuízo para a estratégia implementada, e diante do último ano de governo, começou-se a trabalhar nas propostas que deverão ser deixadas prontas para o próximo governo, pensando-se especialmente na necessidade de consolidar operacional e institucionalmente muitas das reformas já em marcha. Da mesma forma, espera-se deixar como legado uma proposta de nova concepção institucional global do aparato público.

\section{Progressos na modernização da gestão pública}

\subsection{Antecedentes iniciais}

No primeiro governo da coalizão, depois de 17 anos de governo ditatorial, não foram incorporadas iniciativas ou reformas significativas, em matéria de gestão pública, à agenda de governo criada em função das diversas prioridades do momento. Embora se tenha elaborado alguns 
projetos de reforma administrativa, esses não prosperaram por falta de amadurecimento do processo. No entanto, pôs-se em marcha o processo, mediante apoio à incipiente modernização de alguns serviços específicos; realizou-se um trabalho de ordenamento e recuperação do setor público, com a criação de algumas instituições, melhoramento da coordenação dentro do governo, aumento da remuneração do funcionalismo público e a formalização das associações de funcionários, entre outras iniciativas.

O programa do segundo governo da concertação estabeleceu formalmente o compromisso de modernizar a gestão pública. Para isso, o presidente Frei criou, em dezembro de 1994, o Comitê Interministerial de Modernização da Gestão Pública, como entidade responsável pelo incentivo e a coordenação dos esforços nesta área.

Durante 1995 e 1996, promoveu-se, principalmente a partir do Ministério da Fazenda, um programa e uma estratégia de modernização gradual. Desenvolveu-se uma série de iniciativas destinadas a sensibilizar altos dirigentes e funcionários públicos para a necessidade de modernizar a gestão pública. Ao mesmo tempo, introduziu-se os primeiros instrumentos, como indicadores de gestão e compromissos de modernização, acompanhados de uma nova linguagem. Em fins de 1996, podia-se visualizar uma nova linguagem comum entre os funcionários públicos, além do conhecimento e da sistematização de experiências comparadas, institucionalização dos instrumentos de gestão, consolidação de experiências-piloto bem sucedidas e uma aceitação da instauração de uma cultura do desempenho. Não obstante esses progressos, a modernização da gestão pública não era um tema da agenda governamental, não tendo consolidado um conjunto de projetos de peso, e o tema possuía um viés tecnocrático diante da opinião pública, da classe política e dos funcionários.

No início de 1997, criou-se a Divisão de Modernização da Gestão Pública na Secretaria-Geral da Presidência, onde se localiza a Secretaria Executiva do Comitê Interministerial de Modernização da Gestão Pública, a partir de onde se ordena a agenda do governo nesta área. $\mathrm{O}$ Comitê Interministerial elabora o Plano Estratégico de Modernização da Gestão Púbica 1997-2000, firmado pelo presidente da República. Define-se políticas e linhas de ação em cada uma das áreas relevantes como recursos humanos, institucionalidade do Estado, qualidade dos serviços e participação do cidadão, gestão estratégica de governo, ética pública e comunicações.

Durante os últimos dois anos, tem-se trabalhado para desenvolver e implementar o Plano Estratégico 1997-2000. Isto significou, entre outras coisas, desenvolver um discurso político sobre o sentido do processo de modernização, um conjunto de novos instrumentos de gestão e uma série de projetos de peso, como o de gestão pública, o do defensor do 
cidadão, o das contratações públicas, o do prêmio de qualidade, entre outros. O Comitê teve a função de elaborar as políticas de governo na área de modernização, monitorar as tarefas encomendadas aos serviços públicos, coordenar o trabalho de diferentes instituições e executar, direta e permanentemente, os diversos programas do Plano Estratégico.

\subsection{Algumas realizações}

Nesses anos, tem-se conseguido avançar em várias direções. Desde logo, foram colocados na agenda pública os temas de modernização e criados uma série de projetos importantes, que atendem a demandas da cidadania, do setor privado e de atores políticos, o que possibilitou criar as condições para consolidar uma segunda geração de reformas no funcionamento do setor público.

É difícil estabelecer indicadores únicos que traduzam os progressos do processo chileno de modernização. Existem, a este respeito, três formas de abordar esta difícil tarefa: 1) a instalação dos processos e sistemas de gestão; 2) indicadores específicos de gestão por serviço público; 3) indicadores macro da produtividade e/ou legitimidade do setor público.

\subsubsection{Instalação dos processos e sistemas de gestão}

A este respeito, basta recordar alguns dos sistemas de gestão em fase de implementação ou já plenamente implementados no Chile:

- O sistema de gestão estratégica por resultados, que supõe a existência de instrumentos de planejamento e de avaliação do trabalho político-programático do governo. Isto inclui a integração das linhas político-estratégicas do Presidente e do Gabinete, das metas ministeriais e metas de gestão (incluídas nos programas de melhoria da gestão) de cada serviço público. Este sistema, crescentemente integrado à discussão orçamentária, trouxe consigo a possibilidade de sistematizar o processo de planejamento do governo, o estabelecimento de metas concretas e mensuráveis e a atribuição de prioridades às mesmas.

- O sistema de compras e contratações. Este sistema, em plena fase de execução, significa a criação de um sistema único e aberto de informações de todas as compras e contratações públicas, a criação de um sistema de comércio eletrônico para as compras públicas e o fortalecimento da capacidade de gestão das compras de cada uma das unidades administrativas do Estado. A sua principal vantagem está relacionada à transparência da gestão pública (não se pode esquecer que os principais casos de irregularidade administrativa ocorrem nessa esfera) e à eficiência 
da despesa pública (melhor qualidade e menor preço), diante de uma

maior competitividade do mercado.

- O sistema de qualidade e de atenção ao usuário: com base numa política sancionada pelo governo, incentivou-se um conjunto de iniciativas transversais que permitem que hoje se fale de um sistema de gestão de qualidade no setor público chileno. Este sistema inclui o prêmio nacional de qualidade dos serviços públicos, um verdadeiro processo de planejamento e de treinamento em matéria de qualidade do Estado, o programa de inovação, os escritórios de informações e reclamações, o processo de simplificação da tramitação e as cartilhas de direitos dos cidadãos, assim como a conexão on line dos serviços públicos para melhorar a informação e a prestação de serviços à cidadania. Esse sistema focalizou o cidadão-usuário no centro do processo de mudança da gestão pública, colocando a sua satisfação como um dos principais parâmetros de avaliação do desempenho dos funcionários públicos.

Todos esses sistemas foram melhorando de forma contínua a gestão pública. Lamentavelmente, o seu verdadeiro impacto só pode ser medido através de indicadores específicos de cada instituição ou através de indicadores macro que meçam a produtividade ou a satisfação geral dos usuários.

\subsubsection{Indicadores específicos de gestão por serviço público}

Devido à extensão deste ponto, gostaria somente de apresentar um exemplo do Instituto de Normalização da Previdência, que ilustra o tipo de impacto de eficiência e eficácia do processo de modernização da gestão pública chilena. Para maiores informações, sugiro consultar a home page do Comitê na Internet (www.modernizacion.cl) ou a publicação sobre progressos da modernização Resultados al Servicio de la Gente (Comitê Interministerial de Modernização da Gestão Pública, 1997).

\section{Redução do tempo para o fornecimento de respostas}

\begin{tabular}{|c|c|}
\hline Concessão de Benefícios a: & $\begin{array}{c}1990199119921993199419951996 \\
\text { (demora em dias) }\end{array}$ \\
\hline _ Funcionários públicos & $\begin{array}{lllllll}236 & 207 & 177 & 153 & 106 & 80 & 62\end{array}$ \\
\hline - Empregados do setor privado & $\begin{array}{lllllll}152 & 136 & 111 & 92 & 66 & 55 & 34\end{array}$ \\
\hline - Serviço do Seguro Social & $\begin{array}{lllllll}64 & 60 & 46 & 34 & 22 & 20 & 14\end{array}$ \\
\hline
\end{tabular}

Concessão de Pensões a:

\begin{tabular}{|c|c|}
\hline $\begin{array}{l}\text { - EMPART } \\
\text { - Setor Público } \\
\text { - Serviço do Seguro Social }\end{array}$ & $\begin{array}{lllllll}\text { n.d. } & \text { n.d. } & \text { n.d. } & 53 & 47 & 55 & 29 \\
\text { n.d. } & \text { n.d. } & \text { n.d. } & 25 & 19 & 39 & 17 \\
\text { n.d. } & \text { n.d. } & \text { n.d. } & 59 & 57 & 61 & 31\end{array}$ \\
\hline
\end{tabular}


4.2.3. Indicadores macro de produtividade e/ou de legitimidade do setor público.

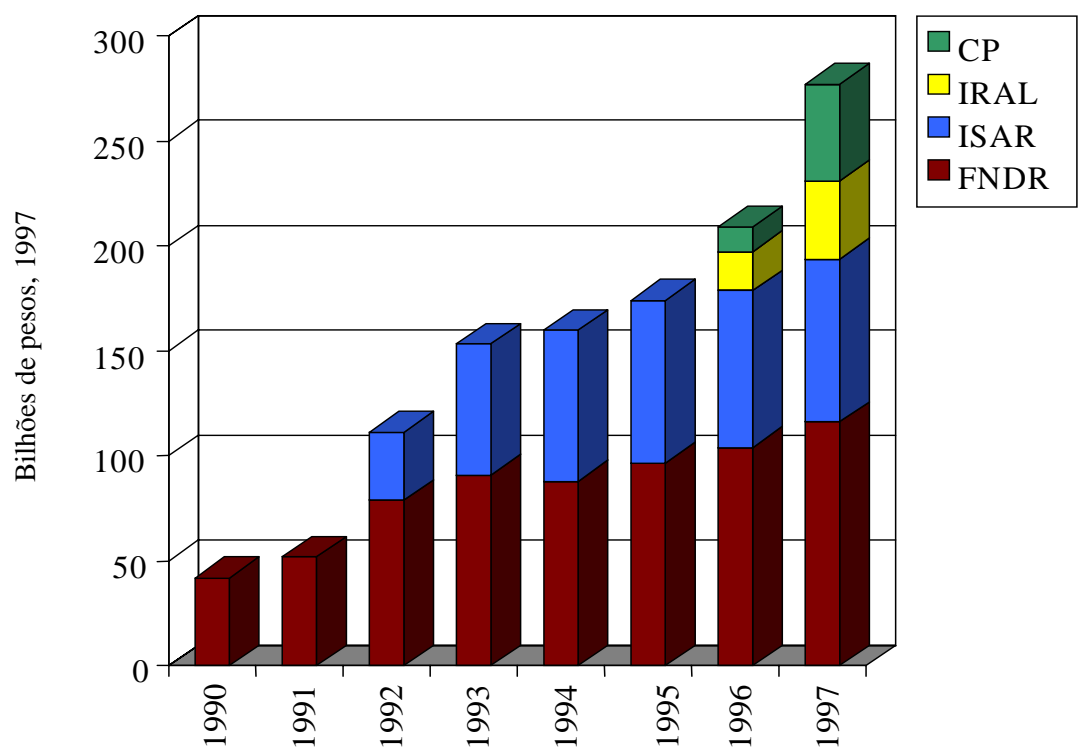

Neste campo, basta mostrar dois gráficos que traduzem a melhoria da gestão macro do Estado chileno. O primeiro tem a ver com o grau de descentralização e o segundo com a produtividade dos funcionários.

\section{Gráfico 1: Grau de descentralização}

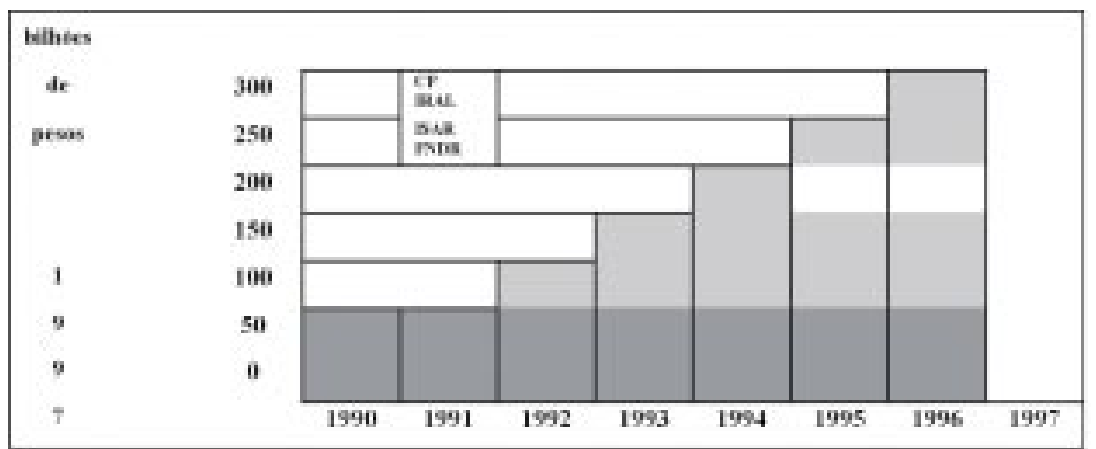

Fonte:Subsecretaria de Desenvolvimento Regional

O governo do presidente Frei conferiu impulso decidido à regionalização e à transferência crescente de recursos a regiões e municípios. O gráfico a seguir mostra os fundos de investimento de gestão regional, 1990-97. 
No início de 1990, as autoridades regionais tinham decisão direta sobre recursos de investimento no valor de 40 bilhões de pesos. Em 1997 decidem sobre recursos de investimento no valor de 280 bilhões, mais do que quintuplicando o valor inicial, o que equivale a $27 \%$ do total do investimento público nacional.

\section{Gráfico 2: Produtividade dos funcionários públicos}

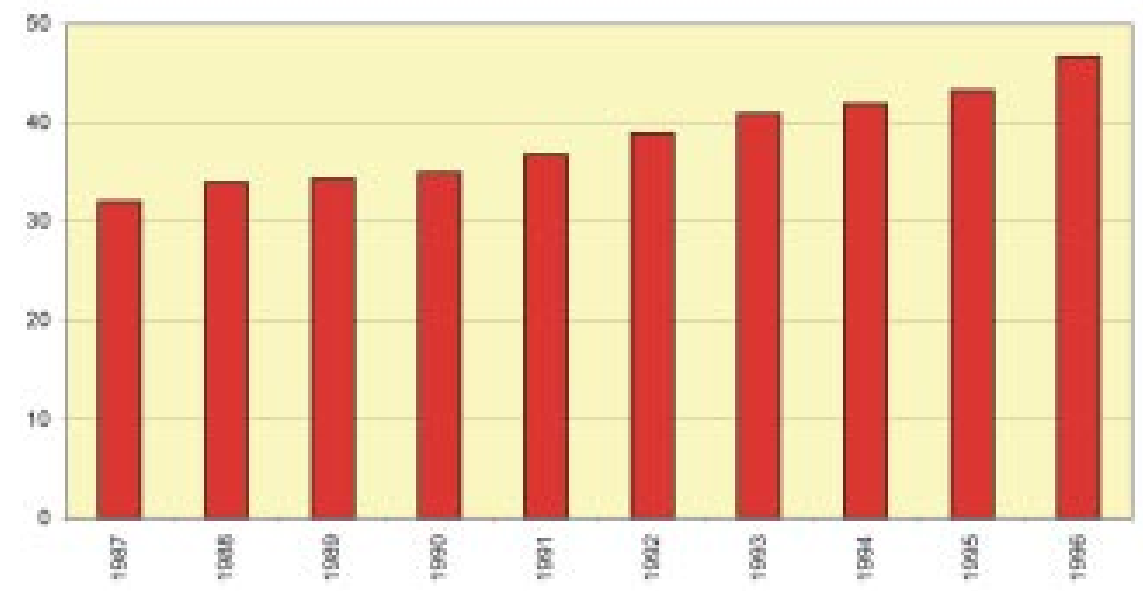

Fonte: Dirección de Presupuesto

Hoje em dia é necessário manter um equilíbrio responsável entre o tamanho e a função do Estado, para enfrentar os desafios de um país moderno, aberto para o mundo, democrático e competitivo, politicamente estável e respeitador das liberdades e dos direitos da cidadania. Neste sentido, a produtividade dos funcionários é chave.

A produtividade do setor público, medida como o montante de recursos administrados por cada funcionário, aumentou em $47 \%$ durante os últimos sete anos.

\section{Desafios do programa de modernização}

O processo de modernização da gestão pública chilena conta hoje com um conjunto de projetos de modernização em curso e outros que aguardam para ser implementados, durante a última etapa do governo do presidente Frei. Mesmo que haja enormes benefícios políticos e econômicos na consolidação da atual agenda de modernização, ainda é necessário um esforço significativo para assegurar sua projeção e sua institucionalização num futuro governo. 
Vários dos projetos pendentes podem se ligar à agenda social e de cidadania do presidente Frei e outorgar dividendos à concertação no próximo período eleitoral. Visando atingir esse objetivo, é necessário que se avance de forma decidida em cinco projetos de alto impacto, os quais têm a particularidade de representar mudanças estruturais, que consolidam e potencializam, a longo prazo, muitas das mudanças já iniciadas no Chile. Estes projetos são:

a) Criação do defensor do cidadão: o projeto de lei institucional está na última fase de revisão e tem como objetivo fortalecer os direitos dos cidadãos e a confiança no setor público. Consagra constitucionalmente a possibilidade de que alguém defenda os cidadãos-usuários em sua relação com um Estado que, em certas circunstâncias, abusa de seu poder ou não provê serviços com a qualidade adequada;

b) instauração de um sistema de gestão pública: o denominador comum nos esforços positivos de modernização e de bom desempenho do governo tem sido fornecido pelas capacidades de administração adquiridas pelos gestores públicos de alto escalão. Durante os últimos governos, não se modificou o status quo existente, o qual tem claras falhas sistêmicas, sendo uma das mais delicadas a questão das remunerações dos executivos do alto escalão. Desde o início de 1998, vem-se trabalhando num projeto para instaurar um sistema de gestão pública que permita, mantendo-se a dependência política dos chefes de serviço, profissionalizar a alta direção, concedendo-lhe as flexibilidades e as ferramentas necessárias para uma melhor gestão. A idéia é estabelecer contratos de desempenho, remunerar adequada e transparentemente, contar com um sistema de seleção mais profissional, prever a obrigação de prestar contas à cidadania, entre outras coisas. $\mathrm{O}$ tema desperta grande interesse na oposição e em setores da concertação, e proporciona um ordenamento que beneficiaria a condução do processo pelo presidente da República. Este projeto também foi anunciado na última prestação pública de contas à nação pelo presidente da República;

c) modernização da institucionalidade reguladora: a retirada do papel produtivo do Estado impôs novas e complexas responsabilidades reguladoras ao setor público. Lamentavelmente, a institucionalidade do Estado está possuída de grande fraqueza para abordar esta tarefa. Com base no relatório de uma comissão de alto nível convocada pelo Comitê Interministerial, elaborou-se um diagnóstico e uma proposta para reformar a institucionalidade reguladora do Estado. Atualmente, o Comitê de Modernização deve sancionar a referida proposta e atribuir prioridade às reformas nas áreas em a regulação é mais urgente;

d) informatização do Estado: desde 1997, a Unidade de Tecnologias da Informação do Comitê dedica-se a massificar o uso intensivo das tecnologias de última geração no governo, elaborando as políticas públi- 
cas nesta esfera e assegurando o seu desenvolvimento permanente. Como

prioridades para o próximo ano e meio, a Unidade deverá consolidar a rede de governo (Intranet) para o intercâmbio de informações e dados entre as instituições públicas, com o conseqüente aumento da eficiência e da qualidade da prestação de serviços públicos e com impacto na vida quotidiana dos chilenos, além de uniformizar o aumento de informações de serviços públicos acessíveis através da Internet. Um componente essencial deste projeto é o reconhecimento da validade legal do documento e a assinatura eletrônica.

e) institucionalização da reforma da administração do Estado: embora a criação do Comitê de Modernização, como instância $a d$ hoc para liderar o processo de modernização e como seu propulsor, tenha sido um acerto político e estratégico, pergunta-se como mesmo se consolidará institucionalmente na estrutura do Estado. Os sistemas de gestão instalados (gestão por resultados, compras, qualidade) as políticas deficitárias (recursos humanos, institucionalização, transparência), e os novos temas da transformação da estrutura e da gestão do Estado demandam uma unidade institucional especializada, pequena em tamanho, mas altamente qualificada e com poder político. Esta é uma das propostas que deveriam ser negociadas politicamente durante o último ano de governo, para ser assumida no futuro.

Pode-se dizer que o processo de modernização encontra-se no ponto crítico, podendo constituir-se um meio de mudança radical na maneira segundo a qual o Estado desempenha suas funções, ou de não seguir adiante, retroceder para antes do próprio ponto de partida, devido às expectativas que foram geradas entre os funcionários, a classe política, o setor privado e a cidadania. Os resultados do próximo ano e meio darão uma resposta a esse desafio. 


\section{Principais projetos e programas impulsionados pelo Comitê de Modernização}

\section{5}

Indicadores de gestão e planejamento estratégico em serviços públicos

A Direção de Orçamento implementou um sistema de indicadores de gestão para identificar objetivos e metas nos serviços públicos; como resultado disso, a maioria dos serviços públicos realizou seu respectivo exercício de planejamento estratégico.

\section{Comitês Bipartites de Treinamento}

Devido à importância e ao impacto do treinamento nos resultados dos organismos públicos e nas perspectivas dos funcionários, estabeleceu-se, por decreto, a criação de comitês compostos de funcionários e dirigentes, cuja finalidade é conceber e aprovar programas de treinamento em cada serviço público. Atualmente, a metade dos serviços públicos conta com eles.

\section{Compromissos de Modernização}

Programa da Secretaria-Geral da Presidência em que os serviços públicos explicitam, ano após ano, seus compromissos de modernização perante o presidente e os cidadãos. É um programa consolidado, que necessitou ir adequando-se continuamente para não tornar-se obsoleto. A partir de 1999, momento em que se consolidam os programas de melhoramento da gestão mencionados mais adiante, esses compromissos adquirirão o caráter de compromissos de simplificação de trâmites e de cartilhas dos direitos dos cidadãos.

\section{6}

\section{Avaliação de Programas Públicos}

Iniciativa acordada com o Parlamento e dependente de uma unidade constituída para estes fins na Direção de Orçamento. Durante 1997, avaliou-se 20 programas governamentais e durante 1998 avaliar-se-ão outros 40 programas públicos, de maneira a conhecer seu impacto em termos de efetividade, eficácia e eficiência.

Novos regulamentos de qualificação

Associado às reformas em matéria de remunerações, os Ministérios do Interior e da Fazenda editaram um decreto, em 1996, que permite às 
repartições modificaram seus regulamentos de qualificação, possibilitando a introdução de elementos que melhorem a mensuração e a classificação do desempenho dos funcionários públicos.

\section{Rede de Treinamento}

Criada em 1996, devido ao sucesso dos comitês bipartites de treinamento, é composta pelos responsáveis na matéria em cada instituição pública. Orienta-se no sentido de apoiar a criação de políticas relativas a treinamento e a implementar oficinas de formação.

\section{Software SISPUBLI}

Um software desenvolvido pelo Serviço Nacional de Treinamento e Emprego, que registra atividades de treinamento, programas, consultorias, níveis de investimento, categoria do pessoal treinado, etc., com o objetivo de avaliação e planejamento adequados dessas matérias.

\section{Memórias e Balanços}

Estabeleceu-se a obrigatoriedade anual, para todos os serviços públicos, de emitir memórias e balanços de suas gestões, que expressem os resultados de suas metas e objetivos e sua situação financeira. Esta disposição foi acordada com o Parlamento, em 1996, na ocassião da aprovação do orçamento da nação.

\section{7}

\section{Internet}

Desde 1995, o governo está fortemente presente na Internet. Visando aumentar o grau de transparência da gestão do aparato estatal, mais da metade das repartições públicas está ligada a um site da Web. Em 1997, o presidente estabeleceu como diretriz, aos dirigentes, a necessidade de aumentar a transferência de importantes fontes de informação à rede.

\section{Prêmio Nacional de Qualidade dos Serviços Públicos}

Elaborou-se um programa para promover e reconhecer a gestão de qualidade nas instituições públicas. O programa foi lançado em outubro de 1997, e dele participaram cerca de 100 serviços públicos, nos quais se realizou uma auditoria em termos de qualidade de serviço e de gestão. Assim, em outubro de 1998, realizou-se a premiação, presidida pelo presidente da República.

\section{Transformação da Corporação de Incentivo à Produção}

Completou-se em 1997 a transformação da CORFO, separando suas atividades de incentivo à produção das de administração de empresas públicas. Criou-se o sistema de administração de empresas e eliminou-se o nível de ministro detido pelo seu vice-presidente. 
O presidente da República convocou uma comissão para apresentar uma proposta de modernização da atividade reguladora. A proposta apresentada em 1998 incluiu uma série de reformas legais e administrativas, objetivando reordenar a composição atual das entidades reguladoras e fiscalizadoras em matéria de utilidade pública, competência, recursos naturais e meio-ambiente.

Eliminação do nível de ministério que detinha a Comissão de Energia

Esta instituição deixou de ter nível ministerial para ser colocada em sua nova dimensão e colaborar na restruturação dos organismos reguladores.

\section{Criação da Unidade de Tecnologias da Informação}

Esta unidade foi criada, tendo sua sede na Divisão de Modernização da Gestão da SEGPRES, e deverá implementar, entre outros, o projeto de uma plataforma comum de conectividade para todas as instituições do Estado.

\section{Informação à Cidadania}

Desde 1997, o Comitê Interministerial de Modernização da Gestão Pública conta com um site na Web, no qual se encontram informações sobre todas as linhas de ação do Plano Estratégico de Modernização da Gestão Pública (http://www.modernizacion.cl). Estão disponibilizadas as guias metodológicas elaboradas como auxílio aos processos individuais dos serviços públicos, publicações sobre as linhas de ação do Comitê e iniciativas como o Prêmio de Qualidade dos Serviços Públicos, entre outras.

\section{8}

\section{O Sistema de Informação de Compras e Contratações do}

Setor Público

Começou-se a desenvolver este sistema, que permite conferir maior transparência, eficiência e concorrência no mercado às compras e contratações do governo, iniciativa dependente da Divisão de Modernização da Gestão Pública da SEGPRES e da CORFO, como parceiro financeiro.

\section{Comércio Eletrônico}

O Ministério da Fazenda e a Divisão de Modernização da Gestão Pública da SEGPRES realizaram, entre março e junho de 1998, um estudo de viabilidade para criar um sistema de intermediação de compras governamentais.

\section{Lei da Probidade}

Aprovação no Congresso de uma lei que complementa os regulamentos sobre as atuações dos funcionários públicos. 
O Comitê Interministerial de Modernização da Gestão Pública emitiu uma instrução para o estabelecimento desses escritórios. Atualmente, 80 organismos públicos contam com tais escritórios.

\section{Programas de Melhoria da Gestão (PMG)}

Em janeiro de 1998, foi estabelecido por lei que todas as repartições da administração central do País devem elaborar, anualmente, programas contendo metas de melhoria de seu desempenho que, de acordo com a obtenção de resultados positivos, permitirão um incremento das remunerações dos funcionários. Estes programas serão implementados a partir de uma perspectiva de coerência e uniformidade entre os indicadores já existentes de gestão, metas ministeriais e compromissos de modernização.

\section{Desconcentração}

Instrução presidencial especifica medidas concretas de transferência de responsabilidades administrativas às regiões. Em execução durante o período 1998-1999, sendo que em alguns ministérios já se iniciou a implementação de planos-piloto há mais tempo. As instituições públicas firmaram 503 compromissos públicos de desconcentração. Esta iniciativa está sendo coordenada pela Divisão de Modernização da Subsecretaria de Desenvolvimento Regional e Administrativo do Ministério do Interior.

\section{Comissão Nacional de Novas Tecnologias da}

Informação e de Comunicações

O presidente da República convocou personalidades e peritos para realizar uma proposta nacional sobre a matéria, mediante sessão presidida em $1^{\circ}$ de julho de 1998 pelo então Ministro da Economia, Sr. Alvaro García, onde se expôs e se aprovou o programa de trabalho, a organização e a metodologia de desenvolvimento nas seguintes áreas: regulação e legislação comercial; as tecnologias da informação e a modernização competitiva; informação e modernização do Estado; desafios sócio-culturais, eqüidade e cidadania. Os resultados das atividades desenvolvidas foram entregues, em 16 de dezembro de 1998, ao presidente da República.

Problema ano 2000

Implementou-se uma equipe de trabalho que elaborou um relatório sobre as instituições a serem afetadas pelo problema de mudança de datas no ano 2000 e sobre como enfrentá-lo.

\section{Plano Piloto de Gestão e Flexibilidade Orçamentária}

O Ministério da Fazenda e a Secretaria-Geral da Presidência estabeleceram convênios de desempenho com os dirigentes de dez serviços públicos, definindo metas a serem alcançadas em troca de maior flexibilidade no manejo dos recursos. 
1 Ver estudo da Transparency International, 1998.

${ }^{2}$ A CORFO (Corporação de Incentivo à Produção) é um organismo público criado com a finalidade de estimular o desenvolvimento produtivo nacional. Esse organismo foi o grande responsável pela industrialização e pela criação de empresas no passado, devido à inexistência de capital privado nacional que pudesse voltar-se para grandes investimentos. Neste sentido, o papel desempenhado pela CORFO foi fundamental no desenvolvimento do Chile.

${ }^{3}$ Nota do revisor: o termo concertação é um neologismo utilizado para especificar a negociação e/ou coalização de vários atores/interesses políticos em determinadas tarefas/issues.

${ }^{4}$ Ver Dirección de presupuesto 96 ou comité de modernización1998

5 Ver Plano Estratégico de Modernização da Gestão Pública 97-2000, Comitê Interministerial de Modernização da Gestão Pública, 1997 (página WEB: www.modernizacion.cl). 


\section{Modernização da gestão pública no Chile: progressos e desafios Claudio Orrego Larrain}

$\mathrm{O}$ artigo aborda o processo de modernização da gestão pública que vem acontecendo nos últimos anos no Chile, a partir do modelo histórico que o caracteriza e das principais rupturas enfrentadas pelo Estado chileno. Sistematiza as dimensões da modernização efetuada, considerando as relações metodológicas e sinergias entre áreas, bem com as desagregações ocorridas e os progressos efetivamente alcançados. São apontados os fatores críticos de sucesso, os focos institucionais de poder, as resistências à mudança e as fontes internacionais de apoio econômico e político.

\section{Modernización de la Gestión Pública en Chile: Progresos y Desafíos Claudio Orrego Larrain}

El artículo trata del proceso de modernización de la gestión pública que viene ocurriendo en los últimos años en Chile, a partir del modelo histórico que lo caracteriza y de las principales rupturas que enfrenta el Estado chileno. Sistematiza las dimensiones de la modernización realizada, considerando las relaciones metodológicas y sinergías entre áreas, y las desagregaciones ocurridas y los progresos efectivamente alcanzados. Se apuntan los factores críticos de suceso, los focos institucionales de poder, las resistencias al cambio y las fuentes internacionales de apoyo económico y político.

\section{Modernisation of Public Management in Chile: Progress and Challenges Claudio Orrego Larrain}

The article deals with the process of modernisation of public management that has been in course in the last years in Chile, starting from the historical model that characterises it and from the main ruptures faced by the Chilean State. It systematises the dimensions of the modernisation achieved, bearing in mind the methodological relations and synergies amongst areas, as well as the disaggregations that took place and progress effectively achieved. The critical factors of success are indicated, the institutional foci of power, resistance to change and the international sources of economic and political support.

Contato com o autor: corrego@minsegpres.cl
Revista do

Serviço

Público

Ano 50

Número 1

Jan-Mar 1999

Secretário

executivo do

Comitê

Interministerial

de Modernização

da Gestão Pública

da República do

Chile e chefe da

Divisão de

Modernização da

Gestão Pública

na Secretaria

Geral da

Presidência.

Advogado

e mestre

em Políticas

Públicas 